\title{
Surgical and nonsurgical treatment of total rupture of the pectoralis major muscle in athletes: update and critical appraisal
}

This article was published in the following Dove Press journal:

Open Access Journal of Sports Medicine

7 October 2010

Number of times this article has been viewed

Jörn Kircher

Christoph Ziskoven

Thilo Patzer

Daniela Zaps

Bernd Bittersohl

Rüdiger Krauspe

University Hospital, Orthopaedic Department, Heinrich-Heine University Düsseldorf, Düsseldorf, Germany
Correspondence: Christoph Ziskoven University Hospital, Orthopaedic Department, Heinrich-Heine University Düsseldorf, Moorenstr. 5, D-40225 Düsseldorf, Germany

Tel +492118 I I796।

Fax $+4921 \mid 8117962$

Email christoph.ziskoven@med. uni-duesseldorf.de
Abstract: The complete rupture of the pectoralis major tendon is an uncommon injury but has become increasingly common among athletes in recent years. This may be due to a higher number of individuals taking part in high-impact sports and weightlifting as well as the use of anabolic substances, which can make muscles and tendons vulnerable to injury. In recent literature, there are only few recommendations to rely on conservative treatment alone, but there are a number of reports and case series recommending early surgical intervention. Comparing the results of the two treatment regimens, there is clear evidence for a superior outcome after surgical repair with better cosmesis, better functional results, regaining of muscle power, and return to sports compared with the conservative treatment. In summary, anatomic surgical repair is the treatment of choice for complete acute ruptures of the pectoralis major tendon or muscle in athletes.

Keywords: pectoralis major, rupture, athlete, conservative treatment, surgical treatment, steroid, tendon, sports injury

\section{Introduction}

Total ruptures of the pectoralis major tendon show a growing incidence over the last decade, particularly within athletes performing strong physical activity. Examples of sport disciplines are weightlifting or body building but also contact sports, such as jiu-jitsu and boxing, or noncontact sports like windsurfing, ${ }^{1-2}$ but there are also uncommon mechanisms of injury such as seatbelt trauma. ${ }^{3}$ A major cause of the increasing importance of this pathologic entity might be the broad use of anabolic steroids. ${ }^{2,4}$

White et $\mathrm{al}^{5}$ reported an incidence of seven pectoralis major tendon ruptures $(28.6 \%$ of the major tendon ruptures) over 2 years among 93,225 army soldiers in a retrospective review. Significant risk factors for major tendon ruptures such as the pectoralis major tendon, Achilles tendon, quadriceps tendon, patellar tendon, and anterior cruciate ligament were Black race, age, male gender, and participation in sports.

It has been widely hypothesized that surgical treatment of pectoralis major ruptures will result in a better functional outcome than nonsurgical treatment, particularly in terms of recovering to full muscular strength, ${ }^{4,6-10}$ but there are also older reports with recommendations for primary conservative treatment. ${ }^{11-13}$ Scott et a ${ }^{11}$ reported good preservation of shoulder strength as measured by dynamometry in three out of four cases and recommended surgical treatment for those with a lack of improvement of shoulder strength. Jones et al ${ }^{12}$ reviewed 81 cases in the English literature until 1988 and found no significant differences in the outcome of conservative treatment and surgery within 2 weeks and 8 months after injury, and only better outcomes with 
significantly more patients with full range of movement and power without pain if the surgical repair was performed in the first 2 weeks after injury.

Komorku et $\mathrm{al}^{13}$ reported a successful three-phase conservative treatment regimen with good results as measured by dynamometry after 9 and 20 months in a paratrooper who got entangled with the risers during a tactical jump out of an aircraft and sustained a pectoralis major tendon rupture.

The authors observed a general trend for early surgical intervention and anatomical repair in sports medicine over the last years with excellent results of minimal invasive approaches which are facilitated by modern instruments and techniques. This general trend influences the surgeon and the patient in decision making about the treatment of choice.

As orthopedic surgeons, we are faced with a very young and active patient population with high demands for immediate treatment and quick reconvalescence, and therefore most patients are willing to undergo early surgical intervention.

Beside the functional and recovery aspects favoring surgery, a retraction of the pectoralis major tendon, which is typical for the nonsurgical treatment, will produce a cosmetically unsatisfying result. Hence, there are only few actual studies focused on an isolated conservative therapeutical approach. ${ }^{13,14}$

\section{Nonsurgical treatment options}

Much of the data regarding nonsurgical treatment of pectoralis major ruptures is based on the treatment of patients without medical consultation after the initial injury. Although minimal or no cosmetic defect is apparent directly after the injury, a visible hollowing of the anterior axillary line typically becomes evident in patients with complete tears within 3 weeks. Patients suffering from chronic ruptures of the pectoralis major tendon present with a noticeable cosmetic defect, with accentuation of the inferior border of the deltoid becoming apparent on abduction or isometric contraction. ${ }^{15}$

Scott et $\mathrm{al}^{11}$ used assessment by dynamometry of the injured and uninjured shoulder and recommended initial nonsurgical treatment and surgical repair only for cases with a power deficit. The patients showed reduction for both adduction and internal rotation in comparison to the uninjured arm.

Nonsurgical treatment usually consists of immobilization in an internally rotated position of the arm using a sling for 3 weeks combined with passive-assistive physiotherapeutic exercise in a period of 6 weeks after injury until healing is achieved. In the following weeks, strengthening exercises can begin and increased gradually in the following weeks and months. ${ }^{14,16}$
There is a lack of information as to whether the strict application of this treatment regimen owns the potential to avoid tendon retraction and therefore achievement of an acceptable cosmetical and functional result in the long term.

\section{Surgical treatment}

Until now, several surgical treatment options have been described in the scientific literature. Most authors favor an axillary approach or a distally extended anterior deltopectoral approach. Operative effort and therefore the risk of complication are increasing with any delay for surgery of the injured tendon.

In 1979 , Berson ${ }^{17}$ described in a case report a primary surgical therapeutic approach to pectoralis major tendon rupture with primary repair of the tendon to the insertion site using absorbable transosseous sutures. In the following years, several case reports on open reinsertion techniques were published, ${ }^{12,18,19}$ and all describing good clinical outcomes. Alternative surgical techniques described are the use of screws and washer ${ }^{20}$ and suture anchors. ${ }^{2,14,21}$ A case series of seven surgically treated athletes either with direct suture of the tear or by transosseous sutures yielded good results. ${ }^{22}$ We identified a total number of 148 cases of pectoralis major tendon ruptures in athletes in the scientific literature accessible via PubMed since the year 2000.

\section{Comparison of operative and nonoperative treatment: yet convincing proof?}

There are several studies comparing operative with conservative treatment, ${ }^{2,7-9}$ and all show advantages of surgical treatment by means of functional recovery. A study from 2001 shows a greater recovery of peak torque and work performed in surgically treated patients, ${ }^{23}$ claiming statistical significance. However, in the method section of the paper, the author remains silent about the surgical method used to repair the tendon rupture.

Merolla et $\mathrm{al}^{24}$ reported about the successful treatment of five patients with acute injuries by reattachment to the insertion site by metallic anchors and an excellent functional result in all cases after 24 months.

Pochini et $\mathrm{al}^{2}$ approved the better functional outcome in the surgical treatment group compared with a nonsurgical treatment in a prospective design with 10 patients in each group. Isokinetic evaluation at $60-\mathrm{deg} / \mathrm{s}$ speed was used as a measure for patient outcome, showing a significant advantage of surgical treatment against nonsurgical treatment and less peak torque deficit. Surgical repair resulted in $70 \%$ excellent, 


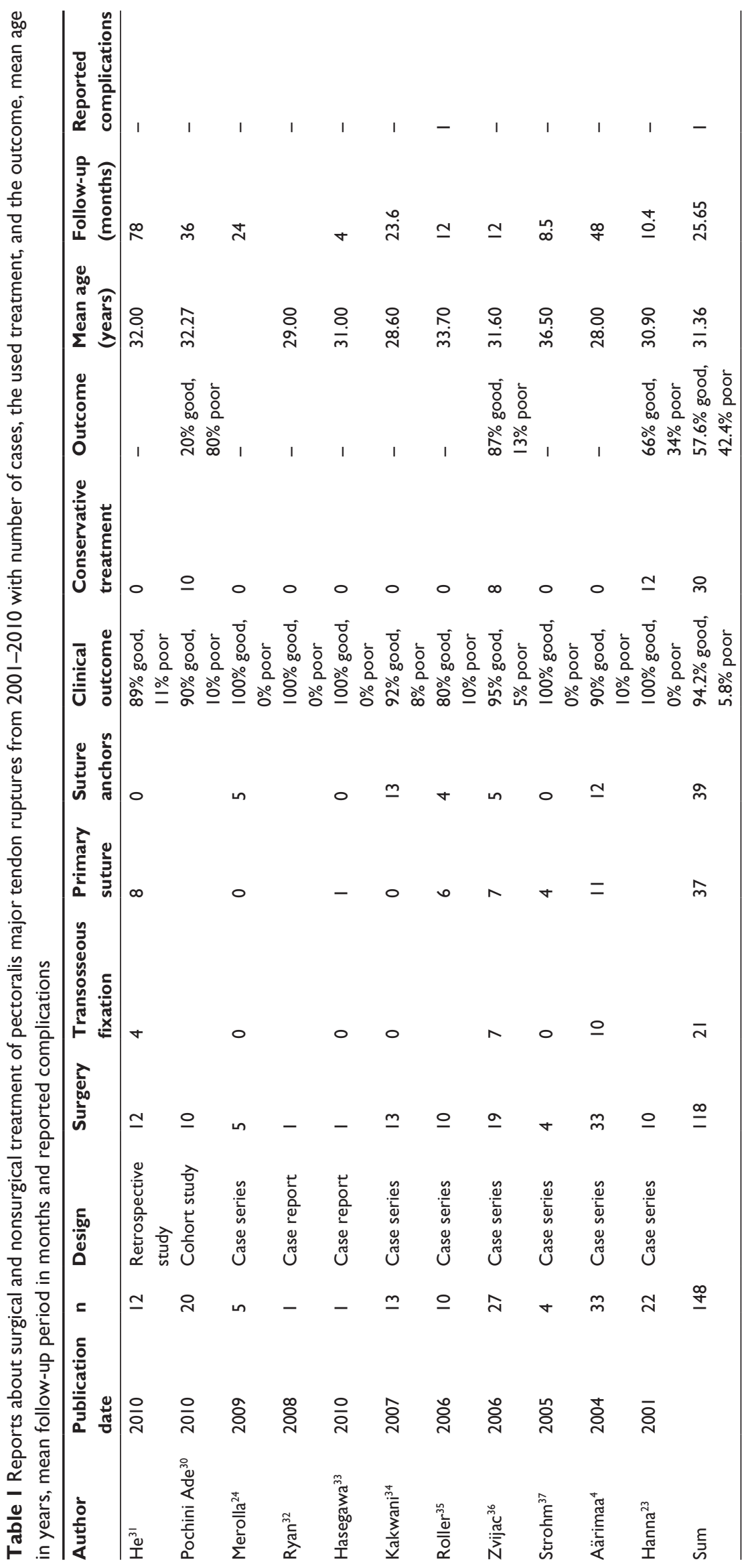


$20 \%$ good, and $10 \%$ bad results compared with $30 \%$ good, $30 \%$ fair, and $40 \%$ bad results in the nonsurgical group. For cases with chronic retraction of the tendon, the authors successfully used hamstring autografts as reinforcement in three patients. Joseph et $\mathrm{al}^{25}$ reported a case of a marked tendon retraction 8 weeks after injury making reattachment impossible, and they used an Achilles tendon allograft for augmentation.

A study comparing immediate and delayed surgical treatment in soldiers found better long-term results in the immediate treatment collectives evaluated by standardized questionnaires. ${ }^{26}$ The results of this study have to be cautiously discussed, because of the retrospective study design on a very small patient collective without any nonsurgical treatment group.

Schmidt and Johann compared the outcomes of four patients with conservative treatment from 1999-2000 with those of nine patients surgically treated from 2001-2006, with four excellent, four good, and one fair result in the operative group and one good and three fair results in the conservative group. ${ }^{14}$ One patient in the surgical group developed heterotopic ossifications without clinical symptoms, and one patient had a wound healing complication. This is a very rare complication with only one more case reported by Purnell in $1988 .^{27}$

Kretzler and Richardson ${ }^{28}$ reported about the surgical treatment of 16 cases with 13 patients who returned to full strength. Two of the remaining patients were operated on more than 5 years after the injury but still had improvement of strength and clinical function. There is a case report by Anbari et $\mathrm{al}^{29}$ about a delayed repair of a sternal rupture 13 years after injury with an excellent functional result.

Concluding, most studies available in the literature favor a surgical treatment of complete tears of the pectoralis major tendon. Unfortunately, most of these studies lack a proper and comparable classification of injuries, as suggested by Tietjen in 1980 (grade I, contusion; grade II, partial lesion; grade III, total lesion with either muscular, muscular portion, musculotendinous, and tendinous location). ${ }^{16}$

Furthermore, even surgical technique is not exactly described in the method section in a number of these publications, making it hard to compare and evaluate the results. Statistical significance is low, resulting from the relatively uncommon occurrence of these injuries and therefore small patient collectives. Last but not least, there are almost no reports of complications after surgical treatment like wound healing complications, infection, and rerupture. Since the misuse of anabolic steroids is at least a possible reason for soft-tissue weakening and tendon rupture in the involved patient collective, ${ }^{30}$ complications are likely to impair the surgical outcome.

\section{Discussion}

Since the available data comparing operative and nonsurgical treatment options are limited, the need for further studies having a proper study design is evident. Also the comparison of the different surgical techniques is still not worked out properly.

The available literature strongly supports the early operative treatment of complete pectoralis major tendon ruptures in athletes with primary repair of the tendon or muscle or reinsertion to the bone by either transosseous sutures, suture anchors, or other devices. This generally yields good functional results, with a high amount of regaining muscle power and return to sports, accompanied by fast recovery and a low complication rate, and therefore is the treatment of choice in this patient group.

\section{Disclosure}

The authors report no conflicts of interest in this work.

\section{References}

1. Dunkelman NR, Collier F, Rook JL, Nagler W, Brennan MJ. Pectoralis major muscle rupture in windsurfing. Arch Phys Med Rehabil. 1994;75(7):819-821.

2. Pochini Ade C, Ejnisman B, Andreoli CV, et al. Pectoralis major muscle rupture in athletes: a prospective study. Am J Sports Med. 2010;38(1):92-98.

3. Harvey KP, Adair JD, Ali MA. Seat belt trauma: pectoralis muscle rupture and delayed mesh repair. J Trauma. 2008;64(3):831-833.

4. Aarimaa V, Rantanen J, Heikkila J, Helttula I, Orava S. Rupture of the pectoralis major muscle. Am J Sports Med. 2004;32(5):1256-1262.

5. White DW, Wenke JC, Mosely DS, Mountcastle SB, Basamania CJ. Incidence of major tendon ruptures and anterior cruciate ligament tears in US Army soldiers. Am J Sports Med. 2007;35(8):1308-1314.

6. Potter BK, Lehman RA Jr, Doukas WC. Pectoralis major ruptures. Am J Orthop (Belle Mead NJ). 2006;35(4):189-195.

7. Bak K, Cameron EA, Henderson IJ. Rupture of the pectoralis major: a meta-analysis of 112 cases. Knee Surg Sports Traumatol Arthrosc. 2000;8(2):113-119.

8. Schepsis AA, Grafe MW, Jones HP, Lemos MJ. Rupture of the pectoralis major muscle. Outcome after repair of acute and chronic injuries. Am J Sports Med. 2000;28(1):9-15.

9. Zeman SC, Rosenfeld RT, Lipscomb PR. Tears of the pectoralis major muscle. Am J Sports Med. 1979;7(6):343-347.

10. Liu J, Wu JJ, Chang CY, Chou YH, Lo WH. Avulsion of the pectoralis major tendon. Am J Sports Med. 1992;20(3):366-368.

11. Scott BW, Wallace WA, Barton MA. Diagnosis and assessment of pectoralis major rupture by dynamometry. J Bone Joint Surg Br. 1992;74(1):111-113.

12. Jones MW, Matthews JP. Rupture of pectoralis major in weight lifters: a case report and review of the literature. Injury. 1988;19(3):219.

13. Komurcu M, Yildiz Y, Ozdemir MT, Erler K. Rupture of the pectoralis major muscle in a paratrooper. Aviat Space Environ Med. 2004;75(1):81-84.

14. Schmidt A, Johann K. [Ruptures of the pectoralis major muscle - clinical results after operative and non-operative treatment]. Sportverletz Sportschaden. 2007;21(4):185-189. 
15. Wolfe SW, Wickiewicz TL, Cavanaugh JT. Ruptures of the pectoralis major muscle. An anatomic and clinical analysis. Am J Sports Med. 1992;20(5):587-593.

16. Tietjen R. Closed injuries of the pectoralis major muscle. J Trauma. 1980;20(3):262-264.

17. Berson BL. Surgical repair of pectoralis major rupture in an athlete. Case report of an unusual injury in a wrestler. Am J Sports Med. 1979;7(6):348-351.

18. Mackenzie DB. Avulsion of the insertion of the pectoralis major muscle. A case report. S Afr Med J. 1981;60(4):147-148.

19. Egan TM, Hall H. Avulsion of the pectoralis major tendon in a weight lifter: repair using a barbed staple. Can J Surg. 1987;30(6):434-435.

20. Kehl T, Holzach P, Matter P. [Rupture of the pectoralis major muscle]. Unfallchirurg. 1987;90(8):363-366.

21. Miller MD, Johnson DL, Fu FH, Thaete FL, Blanc RO. Rupture of the pectoralis major muscle in a collegiate football player. Use of magnetic resonance imaging in early diagnosis. Am J Sports Med. 1993;21(3):475-477.

22. Pavlik A, Csepai D, Berkes I. Surgical treatment of pectoralis major rupture in athletes. Knee Surg Sports Traumatol Arthrosc. 1998;6(2):129-133.

23. Hanna CM, Glenny AB, Stanley SN, Caughey MA. Pectoralis major tears: comparison of surgical and conservative treatment. Br J Sports Med. 2001;35(3):202-206.

24. Merolla G, Campi F, Paladini P, Porcellini G. Surgical approach to acute pectoralis major tendon rupture. G Chir. 2009;30(1-2):53-57.

25. Joseph TA, Defranco MJ, Weiker GG. Delayed repair of a pectoralis major tendon rupture with allograft: a case report. J Shoulder Elbow Surg. 2003;12(1):101-104.

26. Antosh IJ, Grassbaugh JA, Parada SA, Arrington ED. Pectoralis major tendon repairs in the active-duty population. Am J Orthop (Belle Mead NJ). 2009;38(1):26-30.
27. Purnell R. Rupture of the pectoralis major muscle: a complication Injury. 1988;19(4):284.

28. Kretzler HH Jr, Richardson AB. Rupture of the pectoralis major muscle. Am J Sports Med. 1989;17(4):453-458.

29. Anbari A, Kelly JDt, Moyer RA. Delayed repair of a ruptured pectoralis major muscle. A case report. Am J Sports Med. 2000;28(2): 254-256.

30. Pochini Ade C, Ejnisman B, Andreoli CV, et al. Pectoralis major muscle rupture in athletes: a prospective study. Am J Sports Med. 2010;38(1):92-98.

31. He ZM, Ao YF, Wang JQ, Hu YL, Yin Y. Twelve cases of the pectoralis major muscle tendon rupture with surgical treatment-an average of 6.7-year follow-up. Chin Med J (Engl). 2010;123(1):57-60.

32. Ryan SA, Bernard AW. Pectoralis major rupture. J Emerg Med. 2008; Nov 8 [Epub ahead of print].

33. Hasegawa K, Schofer JM. Rupture of the pectoralis major: A case report and review. J Emerg Med. 2010;38(2):196-200.

34. Kakwani RG, Matthews JJ, Kumar KM, Pimpalnerkar A, Mohtadi N. Rupture of the pectoralis major muscle: surgical treatment in athletes. Int Orthop. 2007;31(2):159-163.

35. Roller A, Becker U, Bauer G. Rupture of the pectoralis major muscle: classification of injuries and results of operative treatment. Z Orthop Ihre Grenzgeb. 2006;144(3):316-321.

36. Zvijac JE, Schurhoff MR, Hechtman KS, Uribe JW. Pectoralis major tears: correlation of magnetic resonance imaging and treatment strategies. Am J Sports Med. 2006;34(2):289-294.

37. Strohm PC, Bley TA, Sudkamp NP, Kostler W. Rupture of the pectoralis major muscle - causes, diagnosis, treatment. Acta Chir Orthop Traumatol Cech. 2005;72(6):371-374.
Open Access Journal of Sports Medicine

\section{Publish your work in this journal}

Open Access Journal of Sports Medicine is an international, peer-reviewed, open access journal publishing original research, reports, reviews and commentaries on all areas of sports medicine. The manuscript management system is completely online and includes a very quick and fair peer-review system.

\section{Dovepress}

Visit http://www.dovepress.com/testimonials.php to read real quotes from published authors. 